\title{
ANALISIS FAKTOR KEPUASAAN PENUMPANG BUS TRANS SARBAGITA MENUJU BANDARA UDARA I GUSTI NGURAH RAI
}

\author{
Adi Susanto, SH,MM \\ Dosen STTD \\ J1. Raya Setu No. 89, Bekasi \\ Telp./Fax : (021) 8254640 \\ Bayu Kusumo P. S.ST, MT \\ Dosen STTD \\ J1. Raya Setu No. 89, Bekasi \\ Telp./Fax : (021) 8254640
}

\author{
Ir. Dewa Putu Punia, MT \\ Dosen STTD \\ J1. Raya Setu No. 89, Bekasi \\ Telp./Fax : (021) 8254640 \\ Drs.Ujang Cahyono, MM \\ Dosen STTD \\ J1. Raya Setu No. 89, Bekasi \\ Telp./Fax : (021) 8254640
}

\begin{abstract}
With the Trans Sarbagita Bus public transportation facility that can be used to go to Ngurah Rai Airport, it is expected that the public would prefer the public transportation for airport access or exit. For this research, it is necessary to investigate various factors that make airplane passengers reluctant to use Trans Sarbagita buses as choice of modes to go to or leave the airport. Trans Sarbagita buses still have a low percentage of $2.84 \%$ as a mode of transportation that is chosen by respondents as transportation to the airport. Private cars are in the highest order with a percentage of $32.82 \%$. Using a factor analysis approach from 8 variables that are considered to influence the selection of respondents in using Trans Sarbagita bus transportation or private vehicles can be reduced to only two factors, namely "Subjective Factors" include factors of comfort, safety, safety, cleanliness, and ease of accessibility; then the second is the "Objective Factor" covering travel time, total travel, and reliability. The use of the Moovit Application can help users to get certainty of getting services. Operators are expected to immediately improve their services by using technology-based applications.
\end{abstract}

Keywords: trans sarbagita, performance, service

\begin{abstract}
ABSTRAK
Dengan adanya fasilitas angkutan umum Bus Trans Sarbagita yang dapat digunakan menuju Bandar Udara Ngurah Rai, diharapkan masyarakat lebih memilih angkutan umum tersebut untuk akses masuk ataupun keluar bandara.Untuk itupenelitian ini diperlukan untuk menginvestigasi berbagai faktor yang menyebabkan calon penumpang pesawat enggan menggunakan bus trans sarbagita sebagai pilihan moda untuk menuju maupun meninggalkan bandara. bus trans sarbagita masih memiliki persentase yang rendah yaitu sebesar $2.84 \%$ sebagai moda transportasi yang menjadi pilihan responden sebagai angkutan menuju bandara. Mobil pribadi berada pada urutan tertinggi dengan persentase sebesar $32.82 \%$. Dengan menggunakan metode pendekatan analisis faktor dari 8 variabel yang dianggap dapat memengaruhi pemilihan responden
\end{abstract}


dalam menggunakan transportasi bus trans sarbagita atau kendaraan pribadi dapat direduksi menjadi 2 faktor saja yaitu "Faktor Subyektif" meliputi faktor kenyamanan, keamanan, keselamatan, kebersihan, dan kemudahan aksesibilitas; kemudian yang kedua merupakan "Faktor Obyektif" meliputi waktuperjalanan, totalbiayaperjalanan, dan kehandalan. Penggunaan Aplikasi Moovit dapat membantu pengguna untuk mendapatkan kepastian mendapatkan jasa pelayanan. Operator diharapkan untuk segera meningkatkan pelayanannya salah satunya dengan mengunakan aplikasi berbasis teknologi.

\section{Kata kunci : trans sarbagita, kinerja, layanan}

\section{PENDAHULUAN}

\section{LatarBelakang}

Bandar Udara Internasional Ngurah Rai adalah bandar udara internasional yang terletak di sebelah selatan Bali, Indonesia, tepatnya di daerah Tuban, Kuta, sekitar $13 \mathrm{~km}$ dari Denpasar. Trans Sarbagita merupakan angkutan umum yang dikeluarkan Pemerintah Bali untuk mengatasi masalah kemacetan yang ada di wilayah Sarbagita. Trans Sarbagita mulai beroperasi pada bulan Agustus 2011. Sarbagita merupakan singkatan dari Denpasar, Badung, Gianyar, Tabanan. Wilayah inilah yang akan menjadi tempat beroperasinya bus tersebut. Dengan adanya Trans Sarbagita ini diharapkan masyarakat beralih dari kendaraan pribadi ke kendaraan umum sehingga dapat mengurangi konsumsi bahan bakar minyak (BBM) dan kemacetan. Dalam pengoperasiannya, pada Bus Trans Sarbagita masih ditemukan masalah-masalah yang dihadapi, baik itu minat dari masyarakat terhadap penggunaan bus Trans Sarbagita itu sendiri ataupun masalah mengenai kualitas pelayanan, apakah sudah sesuai dengan kebutuhan penumpang.

\section{Rumusan Masalah}

Berdasarkan latar belakanag penelitian dapat di rumuskan berbagai permasalahan yang mendasari penelitian ini, yaitu :

1. Berapa persen jumlah pengguna bus Trans Sarbagita Bandara Ngurah Rai jika dibandingkan dengan moda transportasi lain 
2. Apa saja faktor yang mempengaruhi pemilihan moda calon penumpang pesawat di Bandara Ngurah Rai

3. Apa persepsi penguna bus Trans Sarbagita terhadap pelayanan bus yang diberikan Sarbagita transportasi menuju Bandara

\section{HASIL DAN PEMBAHASAN}

\section{Penentuan Jumlah Responden}

Pengambilan datadalampenelitianini dilakukandengancaradirectinterview danpengisian kuesioner.PemilihansampeldilakukandenganmetodeSimple RandomSampling.Berdasarkan datayangdiperolehdariPT.AngkasaPuraI (Persero)BandaraI Gusti Ngurah Rai,Balididapatkaninformasibahwajumlah penumpangpesawatpenerbangan domestikyangberangkatdariBandara I Gusti Ngurah Raipadatahun2017adalahsebanyak4.192.679penumpangataurata-rata sebanyak11.486,79penumpangperhari.Dari datatersebut,dapatdihitungjumlah sampelrespondenyangdibutuhkandalampenelitianinidenganmenggunakanpersama an(3.1).Prosespenghitungannyadapatdijabarkansepertiberikutini.

$$
\begin{gathered}
n=\frac{N}{\left(1+N d^{2}\right)} \\
n=\frac{11486,79}{\left(1+11486,79 \times 0,05^{2}\right)} \\
n=386,54
\end{gathered}
$$

Berdasarkanpenghitungan,didapatkanbesaranjumlahsampelminimal yang dibutuhkandalampenelitianiniyaitusebanyak386,54responden (dibulatkan menjadi387).Darihasilsurveidilapanganberhasildidapatkandatayanglengkap atauvaliddarisampelsejumlah387responden. 


\section{Karakteristik Responden}

Tabel KarakteristikResponden

\begin{tabular}{|c|c|c|c|}
\hline ProfillResponden & Kategori & Jumlah & Persentase \\
\hline \multirow{2}{*}{ JenisKelamin } & Pria & 285 & $73,6 \%$ \\
\hline & Wanita & 102 & $26,4 \%$ \\
\hline \multirow{6}{*}{ Usia } & $<20$ tahun & 30 & $7,75 \%$ \\
\hline & $20-29$ tahun & 117 & $30,23 \%$ \\
\hline & $30-39$ tahun & 78 & $20,16 \%$ \\
\hline & $40-49$ tahun & 87 & $22,48 \%$ \\
\hline & $50-59$ tahun & 60 & $15,50 \%$ \\
\hline & $\geq 60$ tahun & 15 & $3,88 \%$ \\
\hline \multirow{7}{*}{ Pekerjaan } & Pelajar/Mahasiswa & 55 & $14,21 \%$ \\
\hline & PegawaiSwasta & 153 & $39,53 \%$ \\
\hline & Wiraswasta & 64 & $16,54 \%$ \\
\hline & PNS/TNI/Polri & 96 & $24,81 \%$ \\
\hline & Pensiunan & 15 & $3,88 \%$ \\
\hline & Tidak Bekerja & 4 & $1,03 \%$ \\
\hline & Lain-lain & 0 & $0,00 \%$ \\
\hline \multirow{6}{*}{$\begin{array}{c}\text { Penghasilanperbul } \\
\text { an }\end{array}$} & BelumBerpenghasilan & 59 & $15,25 \%$ \\
\hline & $<1$ juta & 7 & $1,81 \%$ \\
\hline & $1-2.5$ juta & 70 & $18,09 \%$ \\
\hline & 2.5-5juta & 121 & $31,27 \%$ \\
\hline & 5-10juta & 87 & $22,48 \%$ \\
\hline & $>10$ juta & 43 & $11,11 \%$ \\
\hline
\end{tabular}

Sumber: Hasil Analisa2018

\section{DataPemilihanModaTransportasiMenujuBandara}

Terdapat beberapa moda transportasi yang menjadi pilihan para calon penumpang pesawat yangdimasukkan ke dalam data kuesioner meliputi mobil pribadi, 
sewa.Modaselainyangdisebutkandiatasdikelompokkan

kedalammodalainlain.Distribusipersebarannyadapatdilihatpada Tabel4.2danGambar4.1.

Tabel Pemilihan Moda TransportasiResponden

\begin{tabular}{|c|l|c|c|}
\hline No & Jenis Moda & Jumlah & Persentase \\
\hline 1 & Mobil Pribadi & 127 & $32.82 \%$ \\
\hline 2 & Sepeda Motor & 96 & $24.81 \%$ \\
\hline 3 & Bus Trans Sarbagita & 11 & $2.84 \%$ \\
\hline 4 & Travel & 24 & $6.20 \%$ \\
\hline 5 & Taksi & 94 & $24.29 \%$ \\
\hline 6 & Mobil Sewa & 7 & $1.81 \%$ \\
\hline 7 & Lainnya & 28 & $7.24 \%$ \\
\hline & Jumlah & 387 & $100 \%$ \\
\hline
\end{tabular}

Sumber: Hasil Analisa2018

Kecenderunganpemilihanmodatransportasi dapatdisebabkankarenabanyak hal,misalnyafaktor pekerjaan danpenghasilan.Mereka yang merupakan karyawan ataupekerjayangwaktunyabernilaitinggi,cenderungakanmemilih modatransportasi yangmementingkankecepatan, walaupunbiayanyamungkin

lebihtinggi.Terkaitdenganhubungan

penghasilan,masyarakatdengantingkatekonomi mementingkanaspekkenyamanan,kecepatan,dan denganaspekbiaya.Sebaliknya,masyarakatdengantarafekonomi cenderungmemilihmodatransportasi yanglebihmurahdantidakterlalu antarapemilihanmodadengan tinggiakan cenderung keamanan dibandingkan rendahakan mempermasalahkan fasilitasyangdiberikan.

Faktor yang Mempengaruhi Pemilihan Moda Bus Trans Sarbagita

Indeks Skala Penilaian Pengguna

\begin{tabular}{|c|c|}
\hline Skala & Interpretasi \\
\hline 1 & Sangat Tidak Puas \\
\hline 2 & Tidak Puas \\
\hline
\end{tabular}




\begin{tabular}{|c|c|}
\hline 3 & Cukup Puas \\
\hline 4 & Puas \\
\hline 5 & Sangat Puas \\
\hline
\end{tabular}

Faktor-Faktor yang Menjadi Alasan PenggunaanModaTransportasi

\begin{tabular}{|c|l|c|}
\hline No & \multicolumn{1}{|c|}{ Alasan Pemilihan Moda } & Variabel \\
\hline 1 & Waktu perjalanan & $\mathrm{X} 1$ \\
\hline 2 & Total biaya perjalanan & $\mathrm{X} 2$ \\
\hline 3 & Keamanan perjalanan & $\mathrm{X} 3$ \\
\hline 4 & Kenyamanan dalam perjalanan & $\mathrm{X} 4$ \\
\hline 5 & Kebersihan & $\mathrm{X} 5$ \\
\hline 6 & Keselamatan perjalanan & $\mathrm{X} 6$ \\
\hline 7 & Kemudahan aksesibilitas & $\mathrm{X} 7$ \\
\hline 8 & Kehandalan & $\mathrm{X} 8$ \\
\hline
\end{tabular}

Sumber: Hasil Analisis 2018

Dariberbagaifaktoryangmemengaruhi persepsi respondensehinggaenggan menggunakanbus trans sarbagita tersebut,dapatdisederhanakan ataudikelompokkanmenjadi beberapafaktor saja dengancaramencarihubungan(inter-relationship)antar sejumlahvariabel-variabel

Berdasarkan ketentuan,datalayak untukdianalisispadatahapanselanjutnya apabilapadaKMOandBartlett'sTestnilaiKMOlebihbesardari0,5(KMO $\geq 0,5)$ dannila isignifikansilebihrendahdari0,05(Sig.<0,05).Sedangkanpada Anti ImageMatrices data layak untuk dianalisis apabilanilai Measure of SamplingAdequancylebihbesardari0,5(MSA $\quad \geq 0,5$ ). ApabilanilaiMSAsetiap faktoradayangbelummemenuhi(MSA $\leq 0,5)$, makafaktortersebuttidaklayak untuk dianalisislebih lanjut dan harusdikeluarkandaripengujian, kemudian pengujian diulangikembalisetelahfaktortersebutdihilangkan,demikian seterusnya.

Persepsi PenggunaBus Trans Sarbagita Dibandingkan dengan Kendaraan Pribadi 


\begin{tabular}{|c|l|c|c|c|c|}
\hline \multirow{2}{*}{ No } & \multirow{2}{*}{ Alasan Pemilihan Moda } & \multicolumn{4}{|c|}{ AkumulasiNilai } \\
\cline { 3 - 6 } & & \multicolumn{2}{|c|}{ Trans Sarbagita } & Kendaraan Pribadi \\
\cline { 3 - 6 } & & Jumlah & Rata-Rata & Jumlah & Rata-Rata \\
\hline 1 & Waktu perjalanan & 812 & 2,10 & 1623 & 4,19 \\
\hline 2 & Total biaya perjalanan & 1023 & 2,64 & 1477 & 3,82 \\
\hline 3 & Keamanan perjalanan & 1011 & 2,61 & 1356 & 3,50 \\
\hline 4 & Kenyamanan dalam perjalanan & 847 & 2,19 & 1540 & 3,98 \\
\hline 5 & Kebersihan & 796 & 2,06 & 1576 & 4,07 \\
\hline 6 & Keselamatan perjalanan & 1020 & 2,64 & 1342 & 3,47 \\
\hline 7 & Kemudahan aksesibilitas & 879 & 2,27 & 1653 & 4,27 \\
\hline 8 & Kehandalan & 874 & 2,26 & 1678 & 4,34 \\
\hline
\end{tabular}

Sumber: Hasil Analisis 2018

Berdasarkan data di atas dapat dibuat grafik dengan Spider Web Diagram untuk melihat perbandingan kinerja angkutan umum (bus trans sarbagita) dibandingkan dengan kendaraan pribadi sebagai angkutan menuju bandara. Fungsi lain dari teknik penyajian data menggunakan metode ini adalah dapat diketahui pada sektor mana sajakah dari kinerja bus yang memerlukan pembenahan yang serius. Hasil plot data ke dalam Spider Web dapat di lihat pada gambar

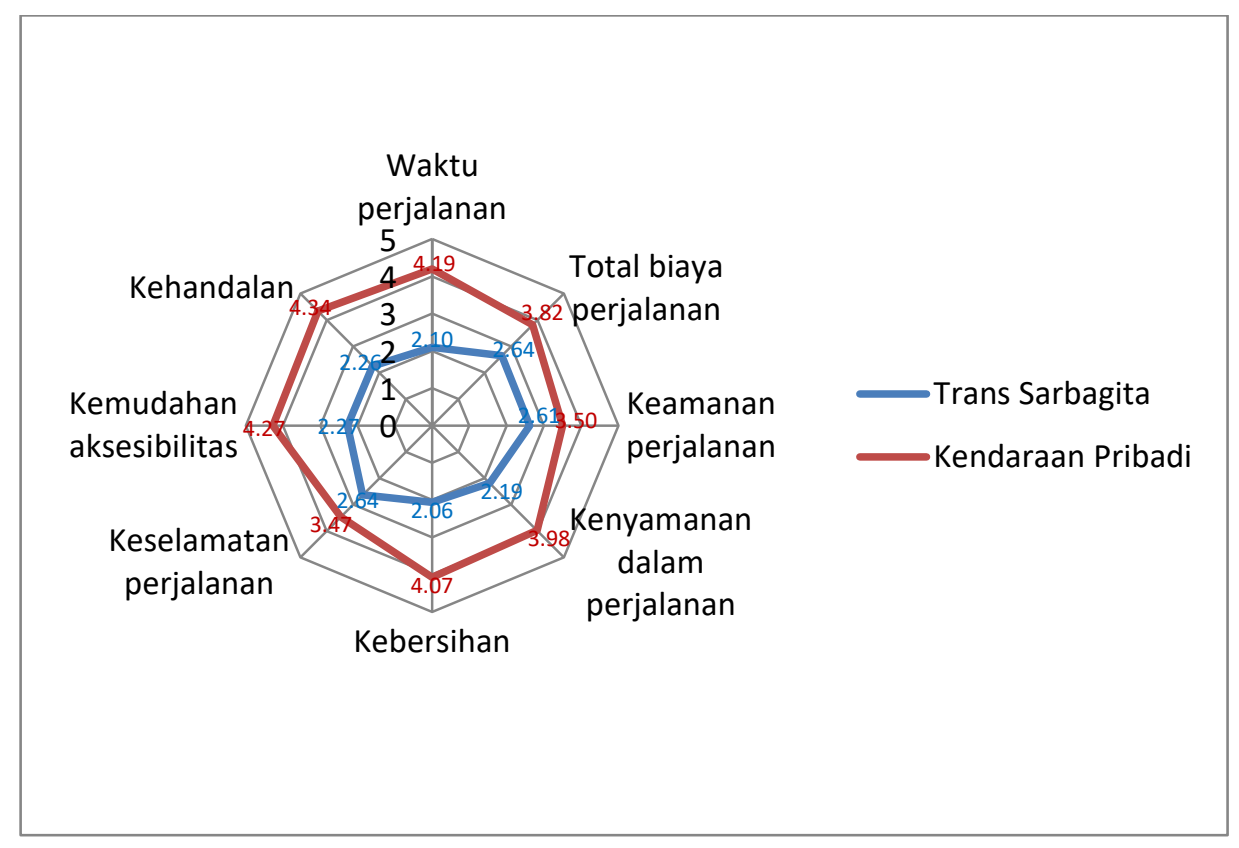


Variabel selanjutnya yang memiliki skor penilaian rendah adalah waktu perjalanan yang memiliki skor 2,10. Waktu perjalanan disini merupakan waktu total yang dibutuhkan seluruh rangkaian perjalanan yang dimulai dari tempat asal perjalanan hingga sampai di tempat tujuan yaitu bandara. Dapat berupa waktu yang dibutuhkan untuk mencapai halte terdekat, waktu untuk menunggu kedatangan bus di halte, serta waktu yang dibutuhkan bus untuk menuju halte yang ada di bandara. Melihat dari penilaian yang diberikan responden menunjukkan bahwa pelayanan waktu perjalanan oleh bus trans sarbagita masih perlu diperbaiki lagi karena masih diatas penilaian "tidak puas", dan jauh dibawah penilaian "cukup puas".

Penilaian responden terhadap variabel kenyamanan perjalanan juga masih rendah yaitu dengan skor 2,19. Berada diatas "tidak puas" dan jauh dibawah “cukup puas" maka variabel ini juga memerlukan banyak perbaikan, baik itu kenyamanan pengguna saat menunggu di halte maupun saat berada di dalam bus. Variabel kebersihan sangat mempengaruhi variabel ini, jika tingkat kebersihan di halte dan bus semakin rendah maka tingkat kenyamanan pengguna akan semakin rendah pula. Selain itu fasilitas yang diperlukan untuk meningkatkan kenyamanan pengguna seperti $A C /$ kipas angin perlu diperhatikan serta berkala kondisinya, baik itu di halte maupun di dalam bus, agar pengguna semakin nyaman menggunakan angkutan trans sarbagita.

Variabel kehandalan juga memiliki skor rendah berdasarkan penilaian responden yaitu 2,26. Dapat diartikan bahwa responden merasa "tidak puas" dikarenakan pelayanan yang diberikan trans sarbagita masih belum konsisten. Responden mengharapkan pelayanan yang konsisten seperti bus yang selalu tersedia saat dibutuhkan, maupun kondisi bus yang selalu dalam kondisi prima. Oleh karena itu, diperlukan pengecekan secara rutin sistem dan kinerja bus trans sarbagita agar bus dapat memberikan pelayanan yang konsisten setiap harinya.

Diatas variabel kehandalan terdapat variabel kemudahan aksesibilitas yang juga mendapatkan skor penilaian yang rendah yaitu 2,27. Artinya responden 
masih "tidak puas" terhadap variabel yang ada pada trans sarbagita ini. Responden menganggap bahwa untuk mencapai bus trans sarbagita masih tergolong sulit. Terutama mengenai keberadaan halte bus terdekat yang tergolong jauh dari lingkungan tempat tinggal responden, sehingga responden membutuhkan angkutan pengumpan yang juga masih tergolong jarang keberadaannya untuk menuju halte bus trans sarbagita tersebut.

Variabel selanjutnya yang memiliki skor 2,61 adalah variabel kemananan perjalanan. Meskipun variabel ini memiliki skor yang lebih tinggi dibandingkan dengan variabel-variabel sebelumnya tetapi variabel ini masih berada pada penilaian "tidak puas". Sehingga tetap perlu dilakukan perbaikan terhadap variabel ini. Sebagian responden menganggap bahwa tingkat keamanan dalam menggunakan trans sarbagita sudah cukup baik, tetapi banyak juga responden yang menganggap bahwa tingkat keamanan dalam menggunakan trans sarbagita ini masih tergolong rendah. Terutama kondisi saat menunggu di halte yang keamanannya dianggap masih rendah. Seperti contoh di beberapa halte terdapat lampu penerangan yang mati, hal ini dapat menimbulkan rasa tidak aman bagi pengguna yang menunggu di halte bus pada malam hari.

Variabel dengan skor tertinggi adalah keselamatan perjalanan dan total biaya perjalanan dengan rata-rata skor penilaian 2,64. Tetapi kedua variabel tersebut skor penilaiannya masih berada dibawah 3 (tiga) artinya menurut responden penilaiannya masih dibawah “cukup puas”.Sehingga untuk meningkatkan pelayanan tersebut menjadi "cukup puas" atau "puas", masih diperlukan berbagai usaha perbaikan, baik itu dari segi fisik maupun sistem. Secara umum masih perlu dilakukan perbaikan pada semua sektor demi peningkatan kepuasan pelanggan terhadap layanan bus trans sarbagita sebagai angkutan umum menuju bandara.

\section{Peningkatan Kinerja dengan Menggunakan Teknologi}

Kehandalan Bus Trans Sarbagita menjadi hal yang banyak dikeluhkan oleh pengguna Bus Trans Sarbagita. Seorang penumpang bias menunggu dibandara 
sampai 2 jam. Hal tersebut dikarenakan jumlah armada yang tidak memadai. Selain harus menambah jumlah armada yang harus diperhatikan adalah kepastian penumpang untuk mendapatkan jasa angkutan umum. Untuk hal tersebut operator bisa memanfaatkan teknologi untuk memonitor lokasi bus. Salah satunya adalah menggunakan aplikasi moovit. Dengan apilkasi ini pengguna bisa mendapatkan informasi rute dan keberadaan Trans Sarbagita. Pengguna juga dapat mengetahui halte yang terdekat dengan pergerakan bus. Dengan adanya aplikasi tersebut pengguna bisa tau kapan untuk menunggu bus.

Kepastian akan mendapatkan jasa layanan angkutan bus menjadi faktor yang sangat penting bagi pengguna. Maka dari itu direkomendasikan bagi operator untuk meningkatkan pelayanannya serta terus berinovasi agar menjadi angkutan yang bisa diandalkan dan diharapkan oleh masyarakat.

\section{SIMPULAN DAN SARAN}

\section{Simpulan}

1. Berdasarkan survei yang dilakukan terhadap 387 responden diperoleh data moda transportasi yang menjadi pilihan responden sebagai angkutan menuju bandara. Mobil pribadi berada pada urutan tertinggi dengan persentase sebesar $32.82 \%$ diikuti dengan sepeda motor dengan $24.81 \%$. Sedangkan bus trans sarbagita masih memiliki persentase yang rendah yaitu sebesar 2.84\%. Dapat disimpulkan dari jumlah persentase tersebut bahwa bus trans sarbagita masih sangat perlu meningkatkan jumlah pengguna agar dapat menjadi transportasi utama menuju bandara.

2. Analisis data dengan metode analisis faktor menunjukkan bahwa dari 8variabel yang dianggap dapat memengaruhi pemilihan responden dalam menggunakan transportasi bus trans sarbagitaatau kendaraan pribadi dapat direduksi menjadi 2 faktor saja yang merupakan gabungan dari beberapa faktor, yaitu "Faktor Subyektif" meliputi faktor kenyamanan, keamanan, keselamatan, kebersihan, dan kemudahan aksesibilitas; kemudian yang 
kedua merupakan "Faktor Obyektif" meliputi waktuperjalanan, totalbiayaperjalanan, dan kehandalan.

3. Seluruh penilaian variabel trans sarbagita berada jauh dibawah penilaian variabel kendaraan pribadi, artinya jika dilihat dari keseluruhan faktor tersebut responden lebih memilih menggunakan kendaraan pribadi sebagai pilihan moda menuju bandara. Variabel penilaian terhadap layanan dan kinerja trans sarbagita dalam rentang skor 1-5, rata-rata skor yang didapatkan dalam kisaran2(dua) hingga 3 (tiga) pada interpretasi "kurang puas" dan belum mencapai “cukup puas". Skor terendahyaitukebersihan $(2,06)$ dan waktu perjalanan $(2,10)$ dan yang tertinggiadalahkeselamatan perjalanan dan total biaya perjalanan $(2,64)$.

\section{Saran}

1. Bagi institusi kedepannya dapat disediakan sarana maupun prasarana untuk mendukung penelitian baik dari segi alat maupun buku-buku referensi terkait analisis faktor suatu data.

2. Bagi instansi terkait khususnya bagi pengelola bus trans sarbagita dapat diadakan upaya perbaikan kinerja dan layanan agar semakin meningkatkan kualitas faktor subyektif dan obyektif yang menjadi faktor utama yang mempengaruhi kualitas pelayanan bus trans sarbagita sehingga dapat meningkatkan jumlah pengguna trans sarbagita sebagai angkutan umummenuju bandara.

3. Bagimasyarakatagar dapatberalih menggunakan bus trans sarbagita dan mengurangi penggunaan kendaraan pribadi sebagai angkutan ke bandara. Hal ini dapat bermanfaat untuk mengurangi tingkat kemacetan yang ada di jalan raya.

4. Penggunaan Aplikasi Moovit bias membantu pengguna untuk memperoleh kepastian pengguna memperoleh layanan. Hal yang bisa dilakukan adalah operator bisa menjalin kerjasama dengan pembuat aplikasi moovit untuk meningkatkan pelayanannya 


\section{DAFTAR PUSTAKA}

Anonim. 2012. Angkutan Umum Trans Sarbagita. Dinas Perhubungan Provinsi Bali. http://www.dishubinkom.baliprov.go.id/id/ANGKUTAN-UMUMTransSARBAGITA, diakses 20 Desember 2014.

Anonim. 2013. Trayek dan Rute Angkutan Umum Trans Sarbagita. Dinas Perhubungan Provinsi Bali. http://www.baliprov.go.id/id/Jalur-Bus-

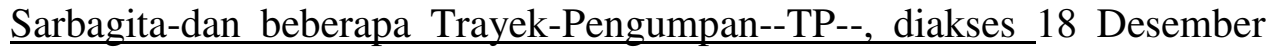
2014.

Black, John A. 1981.Urban Transport Planning : Theory and Practice.CroomHelm: London.

Bruton,M.J.1995.IntroductiontoTransportation Planning.Hutchinson\&Co. (Publisher)ltd.: London.

Jamil,N.A.2012.TeknikSampling.E-

LearningPendidikanKlinikStaseIlmuKesehatanMasyarakat(IKM)

UniversitasIslamIndonesia:Yogyakarta.

JointTransportResearch Centre.2008.TheRoleofAccessibilityinPassengers' Choice ofAirports.International TransportForum:No.2008-14.

Karyawan,I Komang Dwi Oka.2015.Analisis Persepsi Penumpang Terhadap Tingkat Pelayanan Bus Trans Sarbagita (Studi Kasus : Koridor I, Kota GWK). Skripsi Program Studi Teknik SipilUniversitasMahasaraswati :Denpasar.

Kumar,R.1999.ResearchMethodology.Sage Publication:Kuala Lumpur.

Masri,H.2002.AnalisisPengaruh Faktor-FaktorKualitasPelayanan Terhadap KepuasanPelangganJasaTransportasi KeretaApi(StudiKasusPadaPT Kereta Api Indonesia DAOP IV Semarang). Thesis Program Studi MagisterManajemenUniversitasDiponegoro:Semarang.

Setiawan,N.2007.PenentuanUkuranSampelMemakaiRumusSlovindan Tabel

Krejcie-Morgan: TelaahKonsepdanAplikasinya.DiskusillmiahJurusan Sosial Ekonomi Fakultas PeternakanUniversitasPadjajaran: Bandung. 